\title{
Experimental determination of entropy and exergy in low cycle fatigue
}

\author{
Patrick Ribeiro*, Johann Petit, Laurent Gallimard \\ Université Paris Nanterre - 50, rue de Sèvres 92410 Ville d'Avray France
}

\begin{abstract}
Recent works in mechanical fatigue consider that a threshold of entropy exists, the fracture fatigue entropy. The determination of this quantity is usually done considering empirical models for the mechanical power estimation. In this paper, we experimentally observe the existence of a threshold of entropy and exergy in low cycle fatigue for a flat Al-2024 specimen avoiding the use of a model, solely measuring the heat generated during a fatigue test. Results are then compared considering various hypotheses (1D heat dissipation with convection and radiation considered as heat sources, and, heat transfer from a fin with convection and radiation as boundary conditions) to an empirical mechanical model known in the literature and deviations between them are discussed.
\end{abstract}

Keywords: Fracture Fatigue Entropy, Thermography, Exergy

\section{Introduction}

Mechanical fatigue is a phenomenon of materials ageing. Knowing the mechanical behaviour of materials under fatigue enables to estimate their lifetime. Until now, several models have been proposed to estimate the fatigue life of a material. First, models were based on deformation [1,2] and then models have been related to energy with the deformation work $[3,4,5]$. These models allow the estimation of the fatigue life empirically avoiding the use of multiple specimen experimentations, however, the fatigue life predictions are sometimes inaccurate [6]. Another way has also been proposed

\footnotetext{
${ }^{*}$ Corresponding author.

Email address: patrick.ribeiro@parisnanterre.fr (Patrick Ribeiro)
} 
where heat sources analysis is considered as a new component to deal with fatigue features. It appears that heat dissipated in the material is mostly constant during the fatigue lifetime and the dissipation level depends on the loading amplitude [7]. Thus, the idea of an energetic threshold emerges $[8,9,10]$ but cannot be properly interpreted. Recently, new concepts have emerged to study fatigue life such as fracture fatigue entropy $[11,12,13]$ which can be interpreted as the material degradation along fatigue cycles, and exergy, where environment and quality of deformation are taken into account [14]. The main purpose of this study is to determine the fatigue lifetime, for low cycle fatigue, from the entropy threshold and to compare this value with the one obtained using a well-known empirical mechanical model.

\section{Thermomechanical formulation and experimental setup}

\subsection{Thermodynamical framework}

The two laws of thermodynamics are applied to a specimen submitted to fatigue:

$$
\rho \dot{u}=-\operatorname{div} \dot{Q}+\sigma: D \quad \rho \dot{s}=-\operatorname{div}\left(\frac{\dot{Q}}{T}\right)+\dot{\pi}
$$

The second law can be developed as:

$$
\rho \dot{s}+\frac{\operatorname{div} \dot{Q}}{T}-\left(\frac{\dot{Q}}{T^{2}} \cdot \nabla T\right)=\dot{\pi} \geq 0
$$

Where $\dot{\pi}$ is the specific entropy generated flow, produced by the irreversibility of the thermodynamical transformation. Replacing the first principle in the second law, and using the Helmholtz free energy $(\psi=u-T s)$ leads to:

$$
\frac{-\rho}{T}[(\dot{\psi}+s \dot{T})]+\frac{\sigma: D}{T}-\left(\frac{\dot{Q}}{T^{2}} \cdot \nabla T\right) \geq 0
$$

Free energy is considered as a function of multiple state variables (introducing $V_{k}$ a set of internal variables related to phenomena at lower scales) $[15]$ :

$$
\dot{\psi}=\frac{d \psi}{d \epsilon_{e}} \cdot \dot{\epsilon_{e}}+\frac{d \psi}{d T} \cdot \dot{T}+\underbrace{\frac{d \psi}{d V_{k}}}_{A_{k}} \cdot \dot{V}_{k}
$$


To simplify, the small deformation hypothesis can be used in low cycle fatigue $\left(D=\dot{\epsilon}_{e}+\dot{\epsilon}_{p}\right)$. It leads to the expression of the specific entropy generated flow:

$$
\dot{\pi}=\frac{\sigma: \dot{\epsilon_{p}}}{T}+\left(-\frac{A_{k} \dot{V_{k}}}{T}\right)+\left(-\frac{\dot{Q}}{T^{2}} \cdot \nabla T\right) \geq 0
$$

Where:

- $\left[\frac{\sigma: \dot{\epsilon_{p}}}{T}\right]$ is the specific entropy flux generated by plastic deformation

- $\left[-\frac{A_{k} \dot{V}_{k}}{T}\right]$ is the specific entropy flux generated by unrecoverable elastic
deformation stored in the material

- $\left[-\frac{\dot{Q}}{T^{2}} \cdot \nabla T\right]$ is the specific entropy flux generated by heat flux

The fracture fatigue entropy [16] or the maximum entropy generated by irreversibility during fatigue is:

$$
F F E=\int_{0}^{t_{f}} \dot{\pi} d t
$$

$t_{f}$ being the time to failure. In our case, we will concentrate on low cycle fatigue for an Al-2024 specimen. For low hardenable specimen and for high enough test speed, the second and the third terms in equation (5) are generally neglected [15]:

$$
\left|\frac{A_{k} \dot{V}_{k}}{T}\right|<<\left|\frac{\sigma: \dot{\epsilon_{p}}}{T}\right| \quad\left|\frac{\dot{Q}}{T^{2}} \cdot \nabla T\right|<<\left|\frac{\sigma: \dot{\epsilon_{p}}}{T}\right|
$$

The flux of entropy produced reduces in this case to:

$$
\dot{\pi}=\frac{\sigma: \dot{\epsilon_{p}}}{T} \geq 0
$$




\subsection{Experimental procedure and hypotheses}

Experimental tests are done on an Al-2024 specimen using an INSTRON 8501 device allowing repeated traction tests $(R=0)$ for different loading amplitudes comprised between 10.5 and $12 \mathrm{kN}$ and with loading frequencies of 5 and $10 \mathrm{~Hz}$. An infrared camera FLIR A325sc is used to measure surface temperature (working wavelength 7.5-13 $\mu \mathrm{m}$ ). The different configurations are summarised in Table.1 and the material properties are presented in Table.2.

\begin{tabular}{|c|c|c|c|c|}
\hline $\begin{array}{c}\text { Frequency } \\
{[\mathrm{Hz}]}\end{array}$ & $\begin{array}{c}\text { Test Number } \\
{[-]}\end{array}$ & $\begin{array}{c}\text { Load } \\
{[k \mathrm{kN}]}\end{array}$ & $\begin{array}{c}\text { Emissivity } \\
{[-]}\end{array}$ & $\begin{array}{c}\text { Dimensions } \\
{[\mathrm{mm}]}\end{array}$ \\
\hline \multirow{3}{*}{5} & $\mathrm{~N}^{\circ} 1$ & 10.5 & & \\
& $\mathrm{~N}^{\circ} 2-\mathrm{N}^{\circ} 3$ & 11 & & \\
& $\mathrm{~N}^{\circ} 4-\mathrm{N}^{\circ} 5$ & 11.5 & & \\
& $\mathrm{~N}^{\circ} 6$ & 12 & 0.95 & $57 \times 12 \times 2.5$ \\
\hline \multirow{5}{*}{10} & $\mathrm{~N}^{\circ} 7$ & 10.5 & & \\
& $\mathrm{~N}^{\circ} 8$ & 11 & & \\
& $\mathrm{~N}^{\circ} 9$ & 11.5 & & \\
\hline
\end{tabular}

Table 1: Different configurations of tests performed on Al-2024 specimens

\begin{tabular}{|c|c|c|c|c|}
\hline $\begin{array}{c}\text { Density } \\
{\left[\mathrm{kg} / \mathrm{m}^{3}\right]}\end{array}$ & $\begin{array}{c}\text { Thermal Conductivity } \\
{[\mathrm{W} / \mathrm{m} . \mathrm{K}]}\end{array}$ & $\begin{array}{c}\text { Heat capacity } \\
{[\mathrm{J} / \mathrm{kg} . \mathrm{K}]}\end{array}$ & $\begin{array}{c}\text { UTS } \\
{[\mathrm{MPa}]}\end{array}$ & $\begin{array}{c}\text { Young Modulus } \\
{[\mathrm{GPa}]}\end{array}$ \\
\hline 2780 & 121 & 875 & 399 & 73.1 \\
\hline
\end{tabular}

Table 2: Properties of the Al-2024

The main hypotheses used in this study are:

- An unidirectional diffusion of heat, flowing only in the specimen length direction since jaws of the fatigue machine act as temperature sinks. We can verify this assumption experimentally, or using the Biot number (Bi $\left.10^{-5}<<1\right)$.

- The plastic deformation work is completely converted into heat

- The plastic deformation work is assumed homogeneous implying the source term in the heat equation to be space independent. 


\section{FFE calculation}

As shown in section 2, the calculation of the FFE requires the measurement of temperature and plastic deformation work. In the literature, the work of plastic deformation is estimated by empirical models such as the Morrow equation or the Park and Nelson model $[17,18]$. In this work, an estimate of this entropy is obtained by only using experimental results from the temperature measurements. In subsection 3.1, the Park and Nelson empirical model found in the literature is introduced, then, in subsection 3.2, FFE is estimated from infrared thermography.

\subsection{FFE calculation with an empirical mechanical model}

The empirical model used to estimate the entropy generated during fatigue is the Park and Nelson model [5] which relates the cyclic deformation work to the number of cycles endured by the material:

$$
\begin{gathered}
W_{T}=W_{p}+W_{e}=A N_{f}^{\alpha}+B N_{f}^{\beta} \\
A=2^{2+b+c} \sigma_{f}^{\prime} \epsilon_{f}^{\prime}\left(\frac{c-b}{c+b}\right) \quad \alpha=b+c \quad B=\frac{2^{2 b+1}(1+\nu) \sigma^{\prime}{ }^{2}}{3 E_{y}} \quad \beta=2 b
\end{gathered}
$$

Since the elastic part of deformation does not appear in the entropy generation, we only keep the plastic deformation rate which is estimated by:

$$
\sigma: \dot{\epsilon}_{p}=A N_{f}^{\alpha} \cdot f
$$

The fatigue parameters $\left(\sigma_{f}^{\prime}, \epsilon_{f}^{\prime}, b, c\right)$ are estimated using two common laws from literature, the Uniform Material Law (UML) from [19] and the Median Method (MM) from [20]. For Aluminium, the parameters are given by:

$$
\begin{array}{ccccc}
\sigma_{f}^{\prime}=1.67 \text { UTS } & \epsilon_{f}^{\prime}=0.35 & b=-0.095 & c=-0.69 & \mathrm{UML} \\
\sigma_{f}^{\prime}=1.9 \text { UTS } & \epsilon_{f}^{\prime}=0.28 & b=-0.11 & c=-0.66 & \mathbf{M M}
\end{array}
$$

To take into account the mean stress ( since $R=0$ ), we can use the Dowling formulation $[21,22]$, leading to the prefactor:

$$
m=\left(\frac{1-R}{2}\right)^{c / 2 b}
$$


With $R$, the loading ratio. The mean prefactor is obtained for the two fatigue parameters laws giving $m \approx 0.1$.

The entropy generated is finally:

$$
F F E_{P N}=\int_{0}^{t_{f}} \frac{m \cdot A N_{f}^{\alpha} \cdot f}{T} d t
$$

where $F F E_{P N}$ refers to the estimation using Park and Nelson's model. The final value of the FFE presented in the next sections comes from the mean of the values estimated using the Median Method (MM) and using the Uniform Material Law (UML).

\subsection{FFE calculation using thermography}

\subsubsection{Estimation without convection and radiative parts}

Using energy conservation leads directly to the estimation of the fracture fatigue entropy by heat dissipation (HD):

$$
F F E_{H D}=\int_{0}^{t_{f}}\left(\frac{\rho C \dot{T}+d i v \dot{Q}}{T}\right) d t
$$

Note that thermoelastic and thermoplastic couplings are not taken into account, indeed, thermoelasticity vanishes on one cycle and thermoplastic coupling is negligible when the mechanical behaviour varies little with temperature.

The thermal evolution of the material in the present case exhibits two distinct phases. At the beginning of the fatigue test (non stationary phase), plastic deformation is predominant implying a rapid increase in temperature (see figure 1). Then, the work hardening of the material can accommodate the deformation and the temperature is observed to decrease until the second phase. This latter (steady state) shows a stabilisation in the thermal behaviour of the material ; the macroscopic mechanical behaviour has turned elastic nevertheless plasticity remains, as shown in figure 1 by the positive temperature difference with the outside. During this phase, there is an equilibrium between heat production by plastic strain mechanisms and heat losses with exterior.

(a) Heat accumulation estimation:

Heat accumulation $(\rho C \dot{T})$ is evaluated by the use of a spatial mean 
temperature solely dependent on time (considering a homogeneous mechanical deformation). A piece-wise linear spatial mean temperature evolution $\left(T_{m}\right)$ is used to characterise the energy accumulation:

$$
T_{m}(t)=a_{i} t+b_{i} \quad\left(\frac{d T_{m}}{d t}\right)_{i}=a_{i} \quad t \in\left[t_{i}, t_{i+1}\right] \subset\left[0, t_{f}\right]
$$

$a_{i}$ : represents the temperature variation in time obtained by linear fit in the temporal range $\left[t_{i}, t_{i+1}\right]$, this range being included in the entire temporal range $\left[0, t_{f}\right], b_{i}$ a parameter obtained by fit for continuity, and with $t_{f}$ being the time of duration of the test.

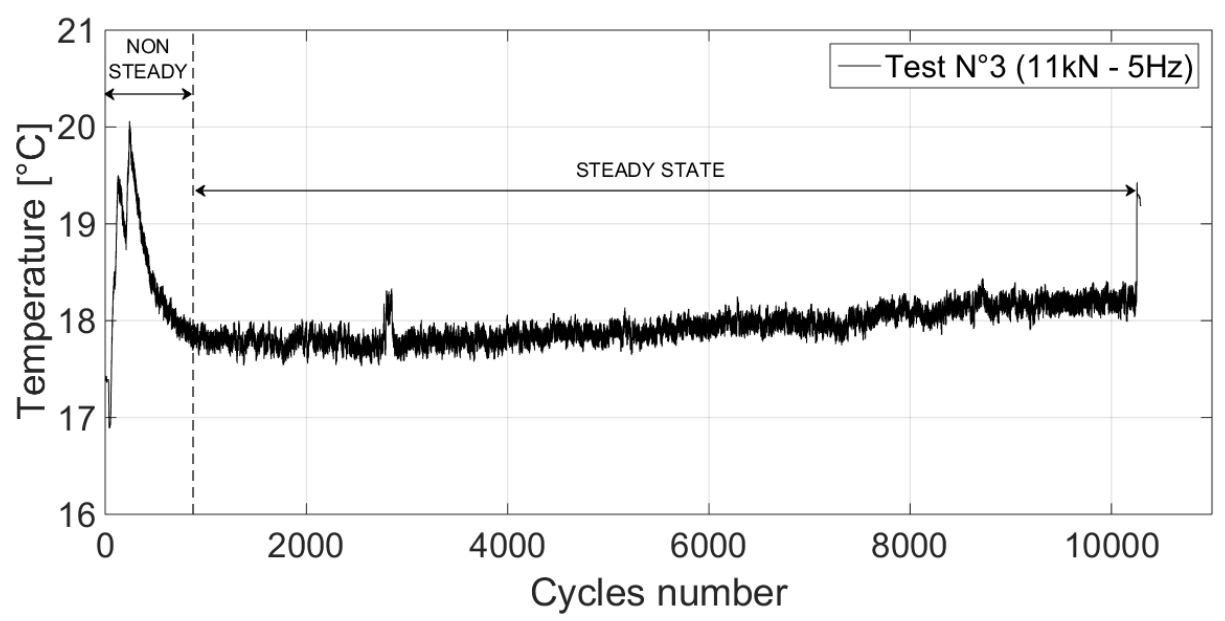

Figure 1: Temperature evolution for the Test $\mathrm{N}^{\circ} 3$ where two different thermal regimes can be observed

The power and entropy accumulated in the sample are calculated using:

$$
\begin{gathered}
P_{a c}=\rho C \dot{T} \approx \rho C \dot{T}_{m} \\
F F E_{a c}=\int_{0}^{t_{f}} \frac{\rho C \dot{T}}{T} d t \approx \int_{0}^{t_{f}} \frac{P_{a c}}{T_{m}(t)} d t=\rho C \sum_{i} \ln \left(\frac{a_{i} t_{i+1}+b_{i}}{a_{i} t_{i}+b_{i}}\right)
\end{gathered}
$$

For the sake of brevity, the integral form of the different FFE expressions will be kept in the following equations.

(b) Heat conduction estimation:

For the heat conduction estimation, considering that heat sources coming from the mechanical deformation are spatially uniform allows the 
use of a parabolic fit for the temperature profile along the specimen (see figure 2). The estimation of the three fit parameters enables the calculation of the thermal conduction power through the material (1D hypothesis), where the spatial temperature profile is fitted at different times to deal with time effects:

$$
T(y)=a_{y} y^{2}+b_{y} y+c_{y} \quad P_{c o}(t)=\operatorname{div} \dot{Q}(t)=-k \frac{d^{2} T}{d y^{2}}(t)=-2 k a_{y}(t)
$$

$$
F F E_{c o}=\int_{0}^{t_{f}} \frac{\operatorname{div} \dot{Q}(t)}{T} d t \approx \int_{0}^{t_{f}} \frac{P_{c o}(t)}{T_{m}(t)} d t=\int_{0}^{t_{f}} \frac{-2 k a_{y}(t)}{T_{m}(t)} d t
$$

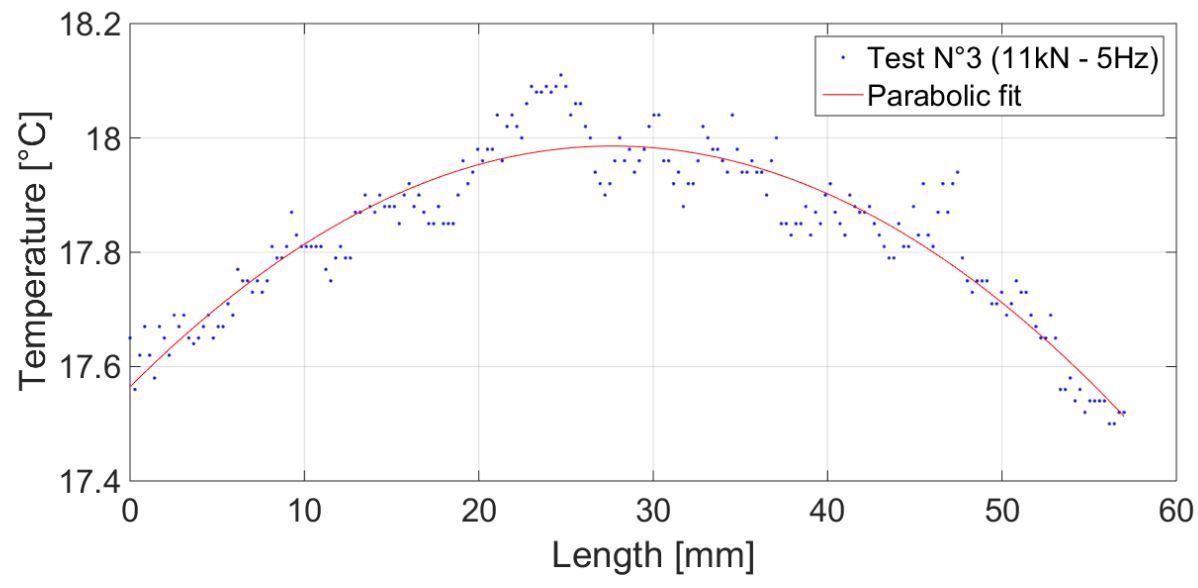

Figure 2: Parabolic fit and measured temperature along the length (centerline) of the specimen at $t \approx 322 s$ (Test $\mathrm{N}^{\circ} 3$ )

The overall generated entropy is then estimated as:

$$
F F E_{H D}=F F E_{c o}+F F E_{a c} \approx \int_{0}^{t_{f}} \frac{-2 k a_{y}(t)}{T_{m}(t)} d t+\int_{0}^{t_{f}} \rho C\left(\frac{\dot{T}_{m}(t)}{T_{m}(t)}\right) d t
$$




\subsubsection{Estimation including convection and radiation}

(a) Considering convection and radiation as heat sources One can improve the former estimation taking into account the convective and radiative parts [10, 23]. The estimation of fatigue fracture entropy is possible considering these two parts as source terms in the equation (16). Thereby the total entropy generated during the fatigue tests can be obtained from Thermal Balance:

$$
F F E_{T B}=\int_{0}^{t_{f}}\left(\frac{\rho C \dot{T}+\operatorname{div} \dot{Q}+P_{c o n v}+P_{r a d}}{T}\right) d t
$$

The specific convecto-radiative power dissipated is estimated by:

$$
\left(P_{\text {conv }}+P_{\text {rad }}\right)=h_{G} \frac{S_{\text {conv }}}{V_{\text {spe }}}\left(T_{m}(t)-T_{0}\right) \quad h_{G}=h_{c o n v}+h_{\text {rad }}
$$

With:

$S_{\text {conv }}=2 \times L \times l+2 \times l \times e_{p}$ is the exchange surface

$V_{\text {spe }}=l \times L \times e_{p}$ is the specimen volume

$L, l, e_{p}$ are the length, width and thickness respectively

The global heat transfer coefficient $h_{G}$ is the sum of a convective part $h_{\text {conv }}$ and a radiative part $h_{\text {rad }}$. The heat convection coefficient is estimated using several correlations from the literature (see Appendix A for more details). For the radiation, a Taylor expansion is used near the environment temperature $T_{0}$ (linearization of the Stefan-Boltzmann law), which is near $288.15 \mathrm{~K}$ :

$$
T_{m}^{4}(t)=T_{0}^{4}+4 T_{0}^{3}\left(T_{m}(t)-T_{0}\right) \quad h_{r a d}=4 \varepsilon \varsigma T_{0}^{3} \approx 5.3 W m^{-2} K^{-1}
$$

With $\epsilon$ the emissivity (taken as 0.95 ) and $\varsigma=5.6710^{-8} \mathrm{Wm}^{-2} \mathrm{~K}^{-4}$, the Stefan-Boltzmann constant. More details on emissivity uncertainties are discussed in Appendix B. The generated entropy from convection and radiation is then estimated by:

$$
F F E_{c o n v}+F F E_{\text {rad }} \approx \int_{0}^{t_{f}} \frac{\left[h_{G} \frac{S_{\text {conv }}}{V_{\text {spe }}}\left(T_{m}(t)-T_{0}\right)\right]}{T_{m}(t)} d t
$$


Finally including all the contributions leads to:

$$
\begin{gathered}
F F E_{T B}=F F E_{H D}+F F E_{\text {conv }}+F F E_{\text {rad }} \\
F F E_{T B} \approx \int_{0}^{t_{f}} \frac{-2 k a_{y}(t)}{T_{m}(t)} d t+\int_{0}^{t_{f}} \rho C\left(\frac{\dot{T}_{m}(t)}{T_{m}(t)}\right) d t+\int_{0}^{t_{f}} \frac{\left[h_{G} \frac{S_{\text {conv }}}{V_{\text {spe }}}\left(T_{m}(t)-T_{0}\right)\right]}{T_{m}(t)} d t
\end{gathered}
$$

(b) Considering convection and radiation as boundary conditions

Another model from the literature permits the estimation of intrinsic dissipation $d_{1}$ in the material $[24,25,26,27,28]$. Based on the heat conduction and assuming an uniform temperature across the thickness and the width, plus, using Neumann boundary conditions leads to a thermal fin like equation (1D hypothesis):

$$
\begin{gathered}
\rho C \dot{\theta}_{T}+\rho C \frac{\theta_{T}}{\tau}-k \frac{\partial^{2} \theta_{T}}{\partial y^{2}}=d_{1} \quad \theta_{T}=\left(T_{m}-T_{0}\right) \\
\tau=\frac{\rho C e_{p} l}{2 h_{G}\left(e_{p}+l\right)} \quad h_{G}=h_{c o n v}+h_{r a d}
\end{gathered}
$$

The entropy is thus directly estimated through:

$$
F F E_{d 1}=\int_{0}^{t_{f}} \frac{d_{1}}{T} d t
$$

The same procedure as previously is used to evaluate heat accumulation. The estimation of $d_{1}$, also assumed uniform along the specimen, can be obtained by fitting the temperature profile along the specimen length (see figure 3):

$$
\theta_{T}=P_{1} \exp ^{y \sqrt{\frac{\rho C}{k \tau}}}+P_{2} \exp \sqrt[-y \sqrt{\frac{\rho C}{k \tau}}]{\frac{\tau d_{1}}{\rho C}}
$$

To take into account time evolution, we can consider a constant $d_{1}$ on the temporal range $\left[t_{i}, t_{i+1}\right]$, the dissipated power is evaluated as (for Thermal Fin):

$$
P_{T F}=\overline{d_{1}}=\left(\frac{1}{t_{f}}\right) \int_{0}^{t_{f}} d_{1}(t) d t \approx\left(\frac{1}{t_{f}}\right) \sum_{n} d_{1}\left(t_{n}\right)\left(t_{n+1}-t_{n}\right)
$$




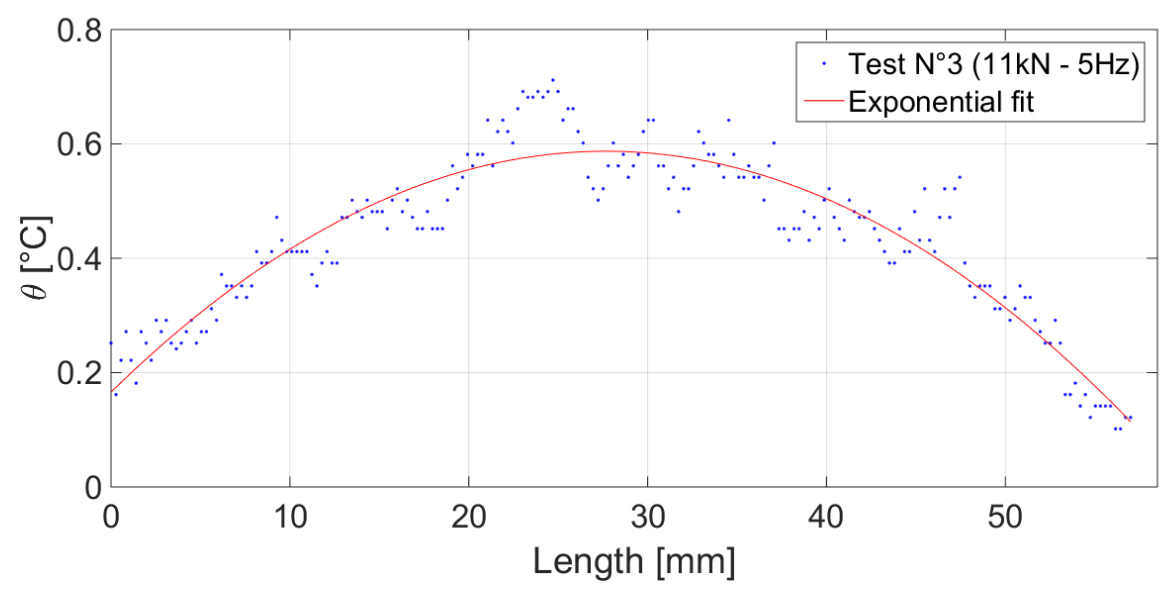

Figure 3: Exponential fit and measured temperature along the length (centerline) of the specimen at $t \approx 322 s$ (Test $\mathrm{N}^{\circ} 3$ )

And the generated entropy is given by:

$$
F F E_{T F} \approx \int_{0}^{t_{f}} \rho C\left(\frac{\dot{T}_{m}(t)}{T_{m}(t)}\right) d t+\int_{0}^{t_{f}} \frac{d_{1}(t)}{T_{m}(t)} d t
$$

\subsubsection{FFE evolution in time}

The temporal evolution of the fracture fatigue entropy can be analysed using an interval time-based integration. The mean time derivative of the fracture fatigue entropy $F \dot{F} E_{j}$ on each interval $\left[t_{j}, t_{j+1}\right]$ is given by:

$$
F \dot{F} E_{j} \approx\left(\frac{1}{t_{j+1}-t_{j}}\right) \int_{t_{j}}^{t_{j+1}} \frac{P(t)}{T_{m}(t)} d t
$$

$P$ being the power corresponding to the quantity under study $\left(P_{a c}, P_{c o}, P_{c o n v}, P_{r a d}\right.$ or $\left.P_{d 1}\right)$.

Another quantity to study temporal evolution, is the cumulative entropy generation in the temporal range $\left[0, t_{j}\right]$ with $t_{j} \leq t_{f}$ which can be calculated using:

$$
F F E_{c} \approx \int_{0}^{t_{j}} \frac{P(t)}{T_{m}(t)} d t
$$

This quantity is very important since it permits to verify if the second principle is fulfilled which requires $F F E_{T B} \geq 0$ and $F F E_{T F} \geq 0$. 
Besides entropy, another thermodynamical quantity called exergy can be used to complete the mechanical analysis.

\section{Exergy calculation}

The thermodynamical study so far is based on the two classical principles. Thus, a new thermodynamical quantity is necessary if we want to extend the thermodynamical study of fatigue.

The notion of quality is important in the field of thermodynamics, indeed, from the point of view of the first principle, an energetical hierarchy does not exist. However, the second principle allows to distinguish the different energies in particular the non equivalence heat-work. To do so, it is possible to create a thermodynamical potential taking into account the environmental effects and allowing the traduction of any energy into an equivalent quantity, a mechanical equivalent potential called exergy (see [29, 30, 31] for details on the history of this quantity), defined as the maximum useful work recoverable from a system in contact with the environment or as a distance from equilibrium.

Exergy in fatigue can be expressed as a linear combination of the first and second principle (considering negligible the work exerted by the room pressure on the material) :

$$
\rho \dot{x}=\rho\left(\dot{u}-T_{0} \dot{s}\right)
$$

Developing each terms leads to [14]:

$$
\rho \dot{x}=\underbrace{-\operatorname{div} \dot{Q}\left(1-\frac{T_{0}}{T}\right)}_{\dot{x}_{q}}+\underbrace{\sigma: \dot{\epsilon_{p}}\left(1-\frac{T_{0}}{T}\right)}_{\dot{x}_{p}}+\underbrace{\sigma: \dot{\epsilon}_{e}}_{\dot{x}_{e}}-\underbrace{\left(-\frac{T_{0}}{T} A_{k} \dot{V}_{k}\right)}_{\text {an }_{k}}
$$

$\dot{x}_{e}$ : Specific exergy flow associated to elastic deformation

$\dot{x}_{q}$ : Specific exergy flow associated to heat transfer

$\dot{x}_{p}$ : Specific exergy flow associated to plastic deformation

$a n_{k}$ : Specific anergy flow associated to internal variables

$C_{a}=\left(1-\frac{T_{0}}{T}\right):$ Carnot Factor 
This equation highlights that the energy of plastic deformation has a lower quality than pure mechanical work (the Carnot Factor acts as the quality factor) making the deformation as a particular mechanical phenomenon. In other terms, if a machine could receive energy accumulated during a material's fatigue, it would get more energy (exergy) from a material's fatigue at higher temperature than a material's fatigue at lower temperature. We will thus concentrate on the exergy of plastic deformation. The plastic exergy generated can be expressed as a function of the FFE:

$$
x_{p}=\int_{0}^{t_{f}} \dot{x}_{p} d t \approx \int_{0}^{t_{f}} \frac{P(t)}{T_{m}(t)}\left(T_{m}(t)-T_{0}\right) d t
$$

The advantage of this quantity is to take into account the effect of the environment temperature on the fatigue irreversibility. Furthermore, for time studies, this quantity can also be treated as the $F F E$ according to eq.35 and eq.36 to get the mean time derivative and the cumulative exergy.

\section{Results and discussion}

Two approaches have been compared to estimate the fracture fatigue entropy of a material. The first approach uses a classical empirical mechanical model (Park and Nelson) and fatigue parameters from literature (Uniform Material Law and Median Method) with a particular prefactor taking into account the mean stress $(R=0)$. The second one is based on the experimental determination of temperature by thermography to estimate the heat flowing in the material. The first estimation (parabolic fit) of the FFE can be refined taking into account convective and radiative parts as source terms. The second estimation (exponential fit) takes convective and radiative parts as boundary conditions. Finally, the exergy of plastic deformation which traduces the thermodynamic quality of the mechanical deformation has also been investigated.

\subsection{Fracture fatigue entropy}

The existence of a threshold, i.e. a constant value of the fracture fatigue entropy for the Al-2024 is here observed experimentally and appears to be an intrinsic parameter of the material (independent of the load and frequency), supporting the work of $[16,17]$ on the fracture fatigue entropy. In addition, the Park and Nelson empirical model (corrected with the mean 


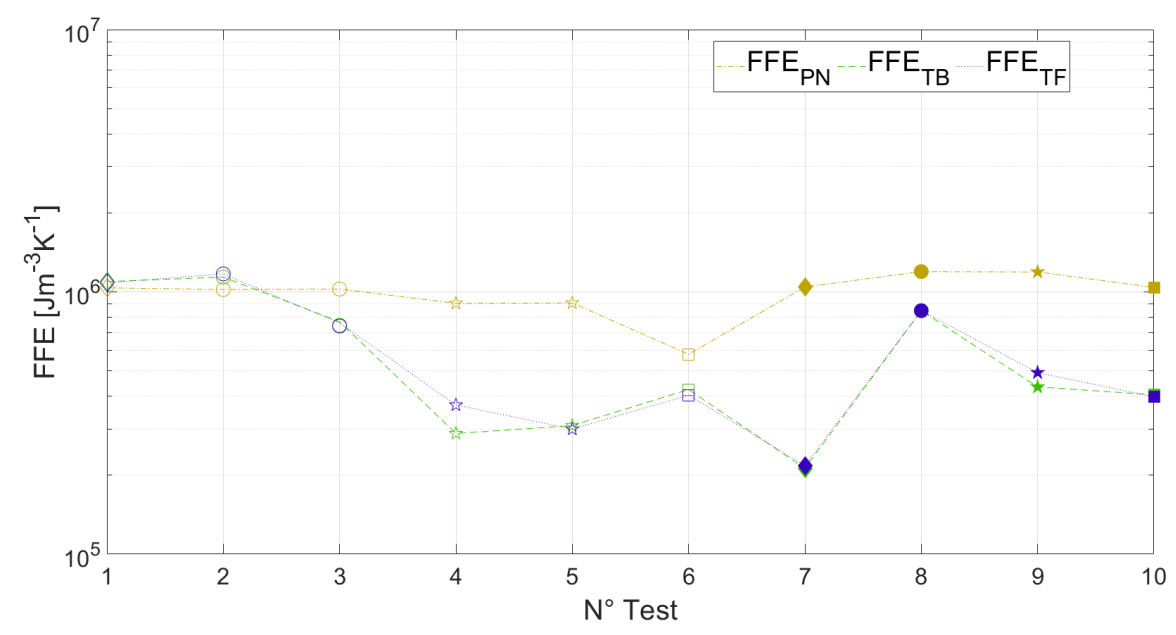

Figure 4: FFE comparison between experimental methods (TB and TF) and empirical model (PN) - Loads : $\diamond: 10.5 \mathrm{kN}-\bigcirc: 11 \mathrm{kN}-$ 柁: $11.5 \mathrm{kN}-\square: 12 \mathrm{kN}$; Frequencies 柁: $5 \mathrm{~Hz}-\star$ : $10 \mathrm{~Hz}$

stress prefactor) is found to be in accordance with the experimental results, where a constant value of the $F F E$ emerges from the various tests, close to the experimental one (see figure 4 ).

From these tests, it can be seen that the components of convection and radiation are negligible compared to pure conduction (the ratio of $F F E_{\text {conv }}+$ $F F E_{\text {rad }}$ to $F F E_{T B}$ is on average equal to $3.13 \%$, see figure 5 ). The low contribution of the convection and radiation on the FFE calculation is also confirmed by the very close estimations using parabolic fitting $\left(F F E_{T B}\right)$ and exponential fitting $\left(F F E_{T F}\right)$ (see figure 6$)$.

The time study presented in fig.7 shows an important part of the FFE created during the first phase (non stationary phase) of the fatigue test i.e. created by the first work hardening $\left(F F E_{a c, j}+F F E_{c o, j}\right.$ or $\left.F F E_{a c, j}+F F E_{d 1, j}\right)$. After this phase, strain is converted into heat almost steadily $\left(F F E_{c o, j}\right.$ or $\left.F F E_{d 1, j}\right)$. The convection and radiation parts appear marginal during the fatigue test. In terms of $F F E_{c}$, this quantity shows two tendencies, entropy accumulates very quickly (fast burst) in the unsteady phase and tends to stabilise (seems to be linear) in the stationary phase. Moreover, the results show positive $F F E_{T B, c}$ and positive $F F E_{T F, c}$ respecting the second law of thermodynamics. 


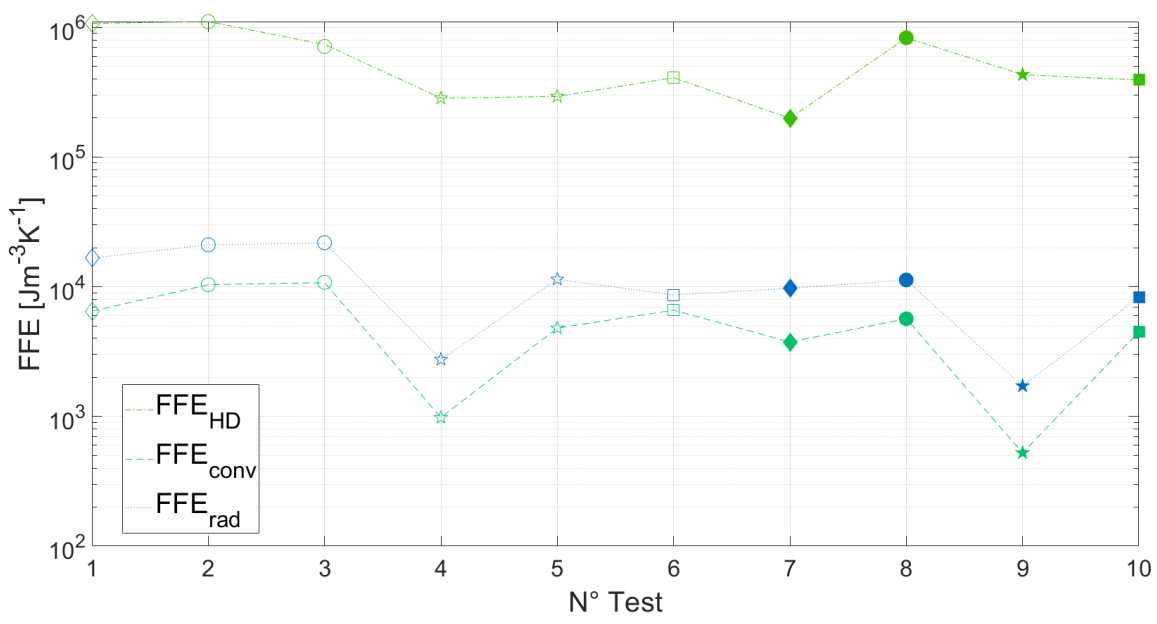

Figure 5: FFE comparison between heat dissipation (HD) and convective (conv) and radiative (rad) parts - Loads : $\diamond: 10.5 \mathrm{kN}-\bigcirc: 11 \mathrm{kN}-\bar{\zeta}: 11.5 \mathrm{kN}-\square: 12 \mathrm{kN}$; Frequencies - 柁: $5 \mathrm{~Hz}-\star$ : $10 \mathrm{~Hz}$

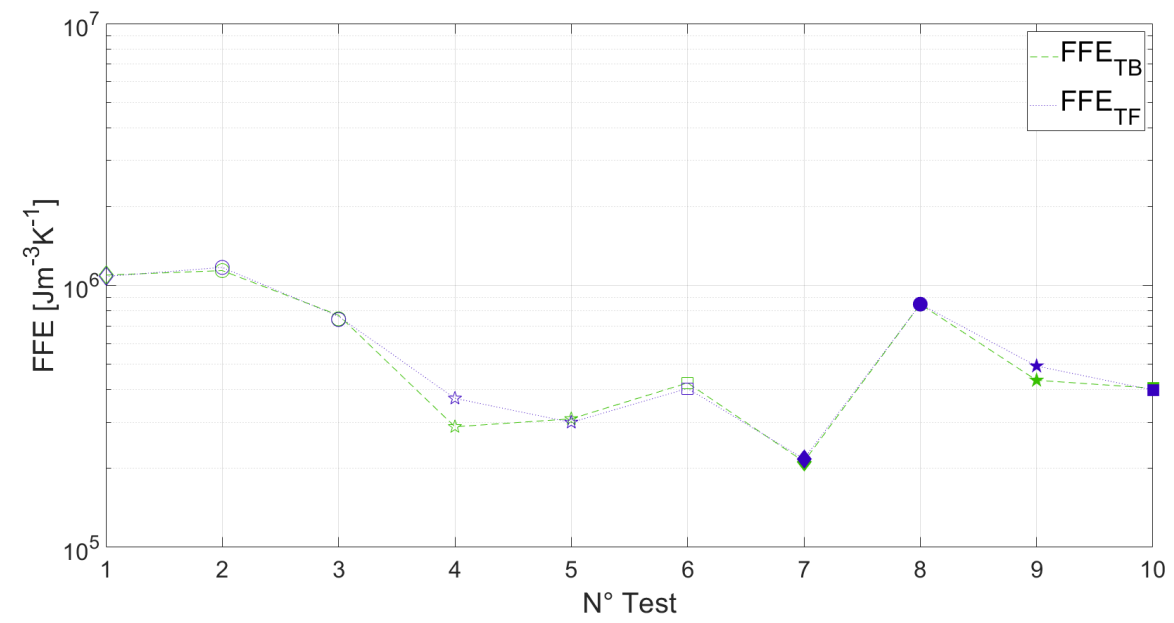

Figure 6: FFE comparison between thermal balance (TB) and thermal fin (TF) including all contributions - Loads : $\diamond: 10.5 \mathrm{kN}-\bigcirc: 11 \mathrm{kN}-\tau^{\star}: 11.5 \mathrm{kN}-\square: 12 \mathrm{kN}$; Frequencies - 岤: $5 \mathrm{~Hz}-\star$ : $10 \mathrm{~Hz}$

\subsection{Exergy of plastic deformation}

The results of the exergy of plastic deformation are plotted in figure 8 . These results consolidate the FFE results where a threshold of exergy of 

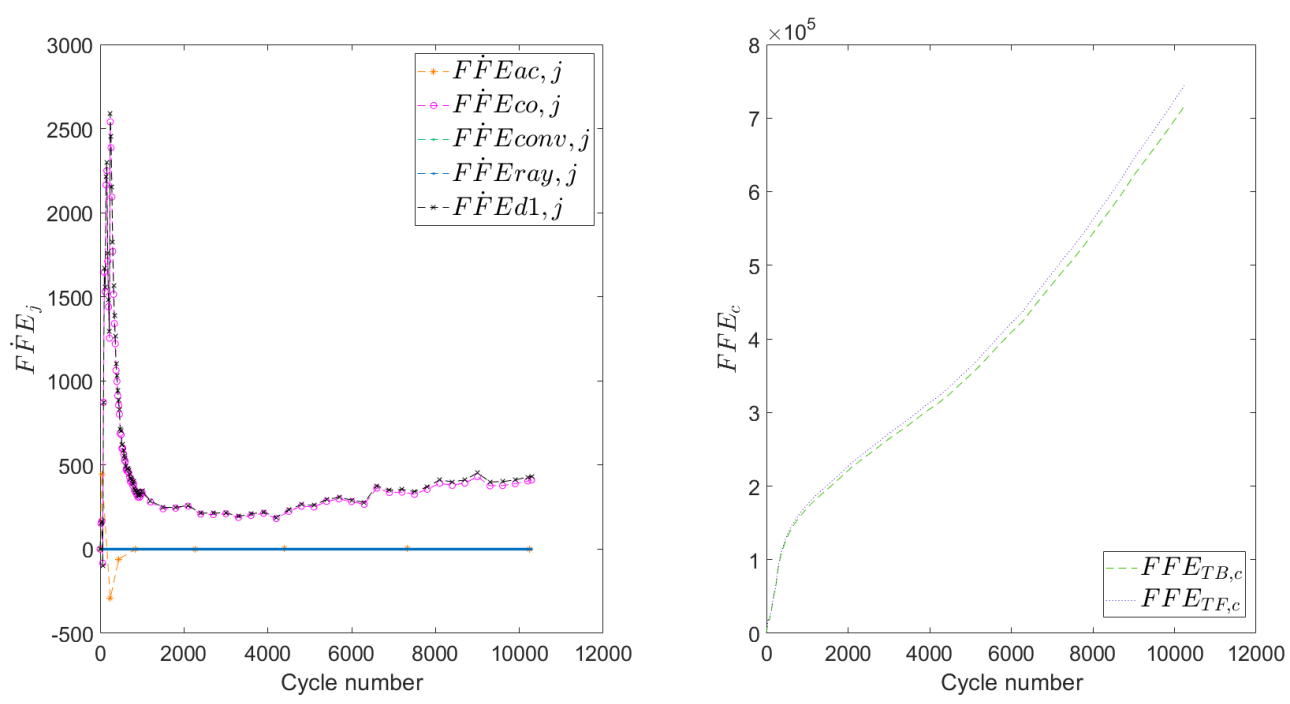

Figure 7: Time interval $F \dot{F} E_{j}$ components and $F F E_{c}$ calculated for the test $\mathrm{N}^{\circ} 3$ as a function of the number of cycles to failure

plastic deformation seems to exist. The advantage of the exergy of plastic deformation is that it takes into account the influence of the environment on the irreversibility of the thermodynamical system and compares different tests under various environmental conditions. Even if, there is no significant difference between the evolution of the $F F E$ and $x_{p}$, it can be seen that taking into account the environment temperature acts as a normalisation.

Like the $F F E_{j}$, estimating a $x_{p}{ }^{j}$ between $\left[t_{j}, t_{j+1}\right]$ shows that the material is highly affected at the beginning of the lifetime of the material. Using the exergy of plastic deformation enables to highlight the thermodynamical degradation of the material. Here, it highlights that the major thermodynamical degradation is caused by the work hardening during the non stationnary phase (see figure 9 versus figure 7). Another interesting feature is that a quick estimate of $x_{p}$ is obtainable using only the non stationary phase (figure $9)$.

\section{Conclusion and perspectives}

In this paper, we have studied low cycle fatigue in a classical thermodynamics framework. From the thermomechanical formulation, one can estimate the fracture fatigue entropy based on temperature measurements 


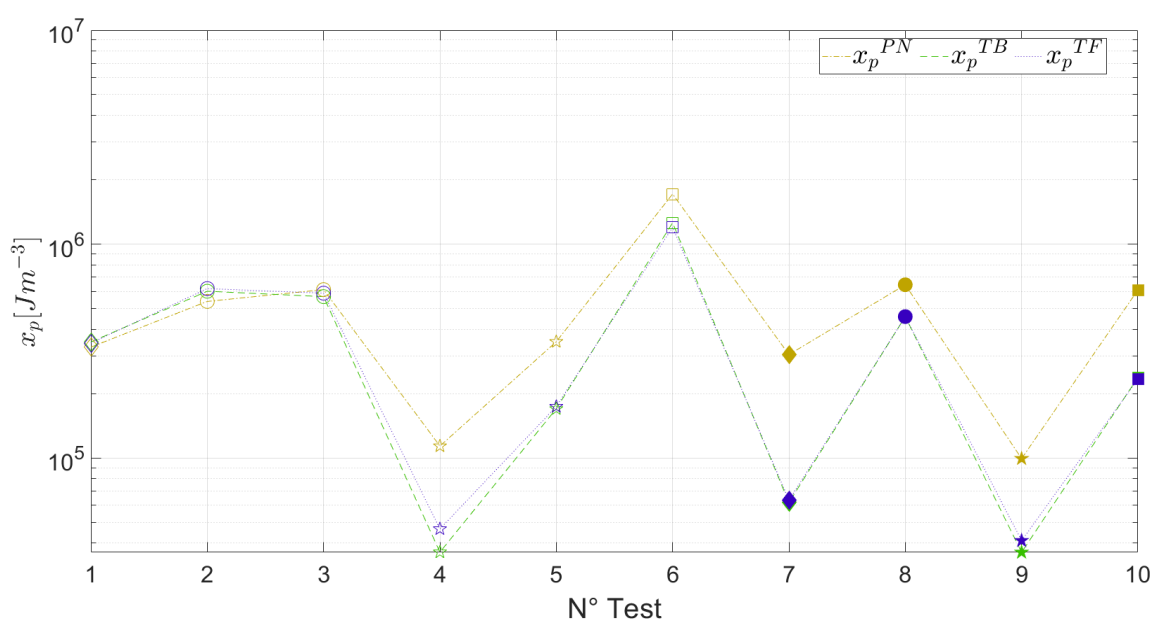

Figure 8: Exergy of plastic deformation dissipated during fatigue for each test, obtained by two experimental methods (TB and TF) and the empirical model (PN)

(where emissivity uncertainty is shown to have a small influence on the FFE estimation). Estimation of this quantity based on a mechanical empirical model is also possible. The various estimations seem to converge towards the fact that a constant fracture fatigue entropy exists, where the Park and Nelson empirical model (corrected with the prefactor for mean stress) produces a value in accordance with the experimental determination procedure. In this study, the influence of environment through convective and radiative parts are negligible, and in terms of exergy of plastic deformation, the results confirm the existence of a threshold, and that thermodynamical degradation is mainly due to the work hardening in the non stationnary phase.

Further tests are suitable to verify the independence of the testing parameter in a broader range of loadings and frequencies. Finally, new tests will be conducted in specific environments where temperature, pressure or chemical potential can vary, in which the use of the exergy of plastic deformation may become the quantity to be studied replacing the fracture fatigue entropy.

\section{Appendix A. Heat transfer coefficient estimation}

Appendix A.1. Dimensionless numbers

The specimen is considered as a vertical plate being submitted to natural convection of air. To estimate heat transfered by convection, we need to 

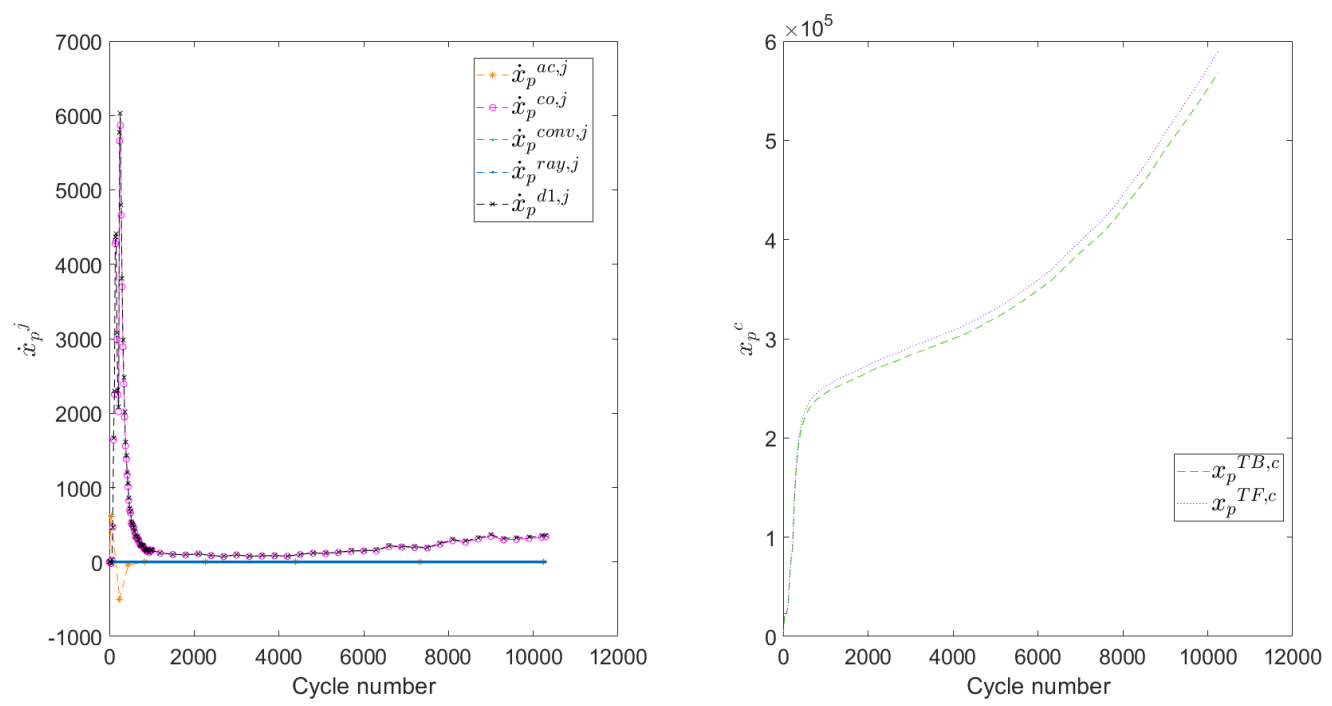

Figure 9: Time interval $\dot{x}_{p}^{j}$ components and $x_{p}{ }^{c}$ for the test $\mathrm{N}^{\circ} 3$ as a function of the number of cycles to failure

estimate the convective heat transfer coefficient. This coefficient is related to the Nusselt number expressed as:

$$
N u=\frac{h_{\text {conv }} L_{c}}{\lambda_{F}}
$$

In natural convection the dimensionless numbers of interest are the Prandtl number and the Grashof number (their product being the Rayleigh number) expressed as:

$$
R a=G r \cdot P r=\frac{g \beta_{c}\left(T_{m}-T_{0}\right) L^{3}}{\nu_{F T} \nu_{F h}}
$$

Thermophysical properties of air are evaluated at the film temperature, i.e. using a mean temperature taken between the vertical surface temperature of the specimen and the air temperature calculated from the empirical formulas in [32]. The estimation of the Nusselt number (and thus $h_{\text {conv }}$ ) is possible using the natural convection correlations on the Rayleigh number from the literature.

\section{Appendix A.2. Correlations}

Several correlations (equations (A.3),(A.4),(A.5) from [23] and equation (A.6) from [33]) exist for vertical plates submitted to natural convection 
leading to very close results for the convective heat transfer coefficient. The mean estimation (using an average on all the correlations) obtained for the convective heat transfer coefficient for each tests is plotted in figure A.10.

$$
\begin{gathered}
N u=\left(0.825+\frac{0.387 R a^{1 / 6}}{\left[1+\left(\frac{0.492}{P r}\right)^{9 / 16}\right]^{8 / 27}}\right)^{2} \\
N u=A(G r \cdot P r)^{1 / 4} \quad A^{4}=\frac{\operatorname{Pr}}{2.43478+4.884 P r^{1 / 2}+4.95283 P r} \\
N u=0.667\left(\frac{P r}{0.952+P r}\right)^{1 / 4} R^{1 / 4}
\end{gathered}
$$$$
N u=0.59 R a^{1 / 4} \quad 10^{4}<R a<10^{9} \quad N u=0.13 R a^{1 / 3} \quad 10^{9}<R a<10^{13}
$$

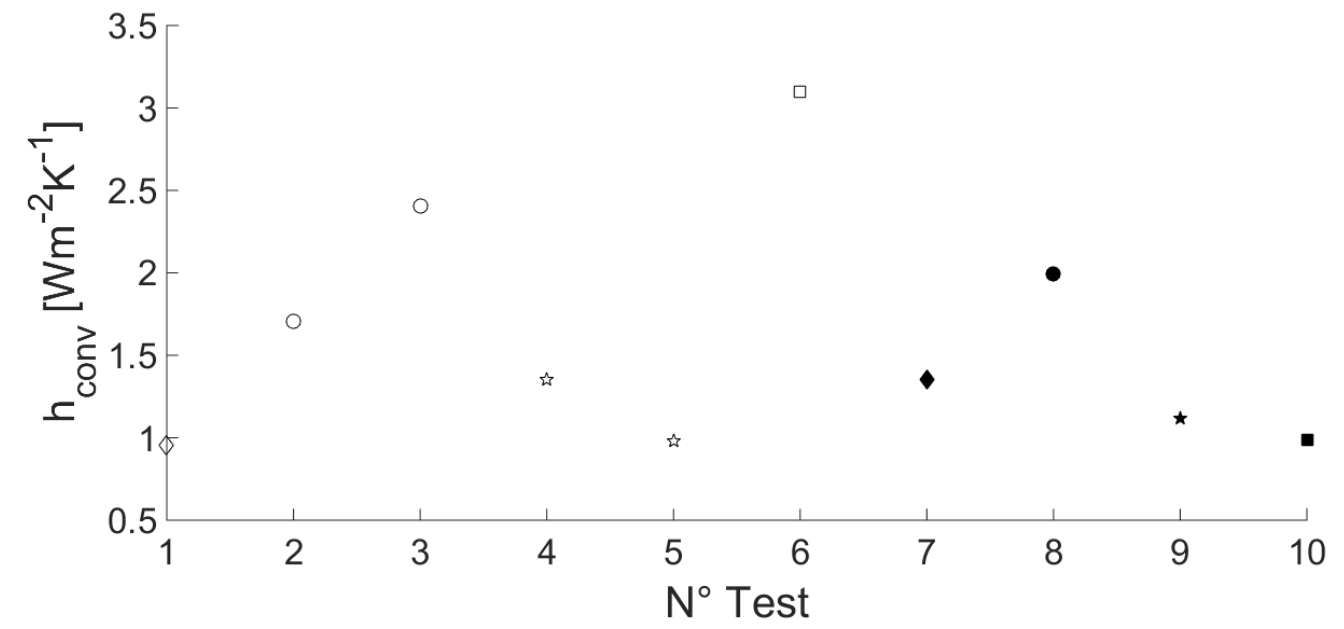

Figure A.10: Mean convective coefficient obtained from the calculation of the different Nusselt numbers given in equations (A.3) to (A.6) - Loads : $\diamond: 10.5 \mathrm{kN}-\bigcirc: 11 \mathrm{kN}-\hbar$ t : $11.5 \mathrm{kN}-\square: 12 \mathrm{kN}$; Frequencies - 就: $5 \mathrm{~Hz}-\star: 10 \mathrm{~Hz}$

We have here considered that our specimen was smooth, in the case of a rough surface, other correlations have to be used [34]. In addition, the former 
correlations are valid for specimens which are not moving. In our case, the loading implies a slight displacement which has to be studied.

\section{Appendix A.3. Correlations validity}

Since the fluid (air) is viscous its velocity is imposed by the specimen (no slip condition). To see if the velocity is imposed by the specimen cycling or through a density gradient (temperature gradient of the fluid), the two components can be compared using the Richardson number (ratio of Grashoff number to the squared Reynolds number) :

$$
R i=\frac{G r}{R e^{2}}=\frac{g \beta_{c}\left(T_{p}-T_{0}\right) L}{v^{2}}
$$

An order of magnitude of the velocity imposed by the specimen can be obtained considering that the velocity is near the velocity of the specimen in the elastic loading regime. Using table.1 and table.2, and the fact that the loading varies from 0 to maximal amplitude during the time $(1 / 2 f)$ where $f$ is the loading frequency, the worst case scenario $(12 \mathrm{kN}-10 \mathrm{~Hz})$ gives the mean velocity as :

$$
v=\frac{\Delta l}{\Delta t} \approx\left(\frac{\Delta \sigma}{E_{y}}\right) \frac{L}{\Delta t}=6.2 \cdot 10^{-3} \mathrm{~m} / \mathrm{s}
$$

The Richardson number is then approximately (taking $T_{m}-T_{0}=1 \mathrm{~K}$ ):

$$
R i=\frac{9.81 \cdot(1 / 293.15) \cdot 1 \cdot 5.7 \cdot 10^{-2}}{\left(6.2 \cdot 10^{-3}\right)^{2}} \approx 50
$$

We see here that the fluid flow is driven by the natural convection, and the velocity being small, the correlations for vertical planes are sufficient.

\section{Appendix B. Emissivity error influence}

When studying a particular range of wavelength $\left[\lambda_{1}, \lambda_{2}\right]$, one can perform the irradiance integration considering fractions of emitted power [35]:

$$
\int_{\lambda_{1}}^{\lambda_{2}} L_{\lambda} d \lambda=\left[f\left(\lambda_{2} T\right)-f\left(\lambda_{1} T\right)\right] \varsigma T^{4}
$$


With :

$$
f(\lambda T)=\frac{15}{\pi^{4}} \sum_{m=1}^{\infty} \frac{e^{m \xi}}{m^{4}}\left(6+6(m \xi)+3(m \xi)^{2}+(m \xi)^{3}\right) \quad \xi=\frac{h_{p} c_{l}}{k_{b} \lambda T}
$$

The comparison between black body and real body radiation is defined by the emission factor $(\varepsilon)$ through a ratio between the black body irradiance and the real body irradiance (in the same conditions):

$$
\varepsilon_{\lambda}(\lambda, T, \theta)=\frac{L_{\lambda}(\lambda, T, \theta)}{L_{\lambda}^{0}(\lambda, T)}
$$

This factor is comprised between 0 and 1 , and depends on the wavelength, temperature, emission angle, the material under study, its surface condition and optical parameters. From this factor, one can evaluate the irradiance temperature $T_{\lambda}$ which is the temperature of a body if it was a black body. In the case of a range of wavelength, we have:

$$
\int_{\lambda} L_{\lambda}(T)=\int_{\lambda} \varepsilon_{\lambda} L_{\lambda}^{0}(T)=\int_{\lambda} L_{\lambda}^{0}\left(T_{\lambda}\right)
$$

In our case, we have hypothesized the value of the emissivity of our painted specimen beeing equal to 0.95 . Recalling that the wavelength range is $\lambda \in[7.5-13] \mu m$, we can analyse the error committed on the temperature measurement if the emissivity was 0.9 or 0.85 (experiments reveal that 0.9 for Al-2024 emissivity is more admissible [36]). Numerical calculation permits to estimate that for $\varepsilon=0.9$ and $\varepsilon=0.85$, the temperature has to be incremented by $3 \mathrm{~K}$ and $6 \mathrm{~K}$ respectively. This shift in the measured temperature does not imply many changes, indeed, the first method requiring a parabolic fit does not need the intercept. In the convection part and in the estimation based on the exponential fit, environment temperature and material temperature are shifted thus temperature difference does not change. Finally, the only part changing is the radiative part, where the radiative equivalent transfer coefficient becomes (using Pascal's triangle):

$$
\begin{array}{lr}
h_{\text {rad }}^{\prime}= & 4\left(\varepsilon-c_{1}\right) \sigma\left(T_{0}+c_{2}\right)^{3} \\
h_{\text {rad }}^{\prime}= & \underbrace{4 \varepsilon \sigma T_{0}^{3}}_{h_{\text {rad }}}+\left[\left(3 * T_{0}^{2} * c_{2}\right)+\left(3 * T_{0} * c_{2}^{2}\right)+c_{2}^{3}\right]-4 c_{1} \sigma\left(T_{0}+c_{2}\right)^{3}
\end{array}
$$

With: $T_{0} \approx 18.7^{\circ} \mathrm{C}, h_{0} \approx 5.36 \mathrm{Wm}^{-2} \mathrm{~K}^{-1}$ and $c_{1}=\{0.05 ; 0.1\}$ and $c_{2}=$ $\{3 ; 6\}$. The calculation of the corrected radiative equivalent transfer coefficient implies $h_{\text {rad }}^{\prime}=\{5.23 ; 5.10\} W^{-2} K^{-1}$ (less than $5 \%$ difference). 


\section{Nomenclature}

\section{Symbols}

$A, B \quad$ Park \& Nelson coefficients

$\mathrm{Pa}$

$a_{i}, b_{i} \quad$ Parameters from the linear fit of the spatial mean temperature in time

$\mathrm{Ks}^{-1}-\mathrm{K}$

$A_{k} \quad$ Thermodynamical force associated to internal variables $\mathrm{J} \mathrm{m}^{-3}$

$a \dot{n}_{k} \quad$ Specific anergy flow associated to internal variables $\quad \mathrm{W} \mathrm{m}^{-3}$

$a_{y}, b_{y}, c_{y} \quad$ Parameters from the parabolic fit of the temperature in the specimen length $\mathrm{Km}^{-2}-\mathrm{Km}^{-1}-\mathrm{K}$

Fatigue strength exponent

C

Specific heat

$\mathrm{J} \mathrm{kg}^{-1} \mathrm{~K}^{-1}$

c

Fatigue ductility exponent

Ca

Carnot factor

$c_{l}$

Light velocity

$\mathrm{ms}^{-1}$

D

Rate of deformation tensor (strain tensor per unit time)

$\mathrm{s}^{-1}$

$d_{1}$

Spatial mean of intrinsic dissipation

$\mathrm{Wm}^{-3}$

$e_{p}$

Specimen thickness

m

$\begin{array}{lll}E_{y} & \text { Young modulus } & \mathrm{Pa}\end{array}$

f Frequency $\quad \mathrm{Hz}$

$F \dot{F} E_{j} \quad$ Mean time derivative of the Fracture Fatigue Entropy $\mathrm{W} \mathrm{m}^{-3} \mathrm{~K}^{-1}$

FFE Fracture Fatigue Entropy $\quad \mathrm{J} \mathrm{m}^{-3} \mathrm{~K}^{-1}$

$F F E_{c} \quad$ Cumulated Fracture Fatigue Entropy $\quad \mathrm{J} \mathrm{m}^{-3} \mathrm{~K}^{-1}$ 


\begin{tabular}{|c|c|c|}
\hline$g$ & Gravitational acceleration & $\mathrm{ms}^{-2}$ \\
\hline$G r$ & Grashof number & - \\
\hline$h_{c o n v}$ & Convection heat transfer coefficient & $\mathrm{Wm}^{-2} \mathrm{~K}^{-1}$ \\
\hline$h_{G}$ & Convecto-radiative heat transfer coefficient & $\mathrm{Wm}^{-2} \mathrm{~K}^{-1}$ \\
\hline$h_{p}$ & Planck constant & Js \\
\hline$h_{r a d}, h_{r a d}^{\prime}$ & Radiation heat transfer coefficient & $\mathrm{Wm}^{-2} \mathrm{~K}^{-1}$ \\
\hline$k$ & Material conductivity & $\mathrm{Wm}^{-1} \mathrm{~K}^{-1}$ \\
\hline$K^{\prime}$ & Cyclic strength coefficient & $\mathrm{Pa}$ \\
\hline$k_{b}$ & Boltzmann constant & $\mathrm{JK}^{-1}$ \\
\hline$L$ & Specimen length & $\mathrm{m}$ \\
\hline$l$ & Specimen width & $\mathrm{m}$ \\
\hline$L_{c}$ & Characteristic length & $\mathrm{m}$ \\
\hline$L_{\lambda}\left(L_{\lambda}^{0}\right)$ & Spectral irradiance (black body) & $\mathrm{Wm}^{-2} \mathrm{~K}^{-1}$ \\
\hline$m$ & Dowling prefactor for mean stress & - \\
\hline$n^{\prime}$ & Cyclic strength exponent & - \\
\hline$N_{f}$ & Number of cycles to failure & - \\
\hline$N u$ & Nusselt number & - \\
\hline$P$ & Dissipated power & $\mathrm{W}$ \\
\hline $\operatorname{Pr}$ & Prandtl number & - \\
\hline$\dot{Q}$ & Surface heat flux & $\mathrm{W} \mathrm{m}^{-2}$ \\
\hline$R a$ & Rayleigh number & - \\
\hline$R e$ & Reynolds number & - \\
\hline$R i$ & Richardson number & \\
\hline
\end{tabular}




\begin{tabular}{|c|c|c|}
\hline$S$ & Surface convected and radiated & $\mathrm{m}^{2}$ \\
\hline$s$ & Specific entropy & $\mathrm{J} \mathrm{kg}^{-1} \mathrm{~K}^{-1}$ \\
\hline$\dot{s}$ & Specific entropy flux & $\mathrm{W} \mathrm{kg}^{-1} \mathrm{~K}^{-1}$ \\
\hline$t$ & Time & $\mathrm{S}$ \\
\hline$T$ & Absolute temperature & $\mathrm{K}$ \\
\hline$\dot{T}$ & Absolute temperature variation & $\mathrm{Ks}^{-1}$ \\
\hline$T_{0}$ & Absolute environment temperature & $\mathrm{K}$ \\
\hline$t_{f}$ & Time to failure & $\mathrm{S}$ \\
\hline$t_{I}$ & Time to the beginning of the steady state & $\mathrm{s}$ \\
\hline$T_{m}$ & Spatial mean temperature & $\mathrm{K}$ \\
\hline$\dot{T}_{m}$ & Spatial mean temperature variation & $\mathrm{Ks}^{-1}$ \\
\hline$u$ & Specific internal energy & $\mathrm{J} \mathrm{kg}^{-1}$ \\
\hline$\dot{u}$ & Specific internal power & $\mathrm{W} \mathrm{kg}^{-1}$ \\
\hline$U T S$ & Ultimate tensile strength & $\mathrm{Pa}$ \\
\hline$V$ & Volume & $\mathrm{m}^{3}$ \\
\hline$v$ & Velocity & $\mathrm{ms}^{-1}$ \\
\hline$\dot{V}_{k}$ & Rate of variation of internal variables & $\mathrm{J} \mathrm{m}^{-3}$ \\
\hline$V_{\text {spe }}$ & Volume of the specimen & $\mathrm{m}^{3}$ \\
\hline$\dot{W}$ & Work of deformation per unit time & $\mathrm{W} \mathrm{m}^{-3}$ \\
\hline$\dot{W}_{e}$ & Work of elastic deformation & $\mathrm{J} \mathrm{m}^{-3}$ \\
\hline$\dot{W}_{p}$ & Work of plastic deformation & $\mathrm{J} \mathrm{m}^{-3}$ \\
\hline$\dot{W}_{T}$ & Work of total deformation & $\mathrm{J} \mathrm{m}^{-3}$ \\
\hline$\dot{x}$ & Specific exergy flux & $\mathrm{W} \mathrm{kg}^{-1}$ \\
\hline
\end{tabular}




$\begin{array}{llr}\dot{x}_{e} & \text { Specific exergy flow associated to elastic deformation } & \mathrm{W} \mathrm{m}^{-3} \\ x_{p} & \text { Specific exergy associated to plastic deformation } & \mathrm{J} \mathrm{m}^{-3} \\ \dot{x}_{p} & \text { Specific exergy flow associated to plastic deformation } & \mathrm{W} \mathrm{m}^{-3} \\ \dot{x}_{q} & \text { Specific exergy flow associated to heat transfer } & \mathrm{W} \mathrm{m}^{-3} \\ y & \text { Spatial variable } & \mathrm{m}\end{array}$

\section{Greek Symbols}

$\alpha, \beta \quad$ Park \& Nelson exponents

$\begin{array}{lll}\beta_{c} & \text { Thermal expansion coefficient } & \mathrm{K}^{-1}\end{array}$

$\varepsilon \quad$ Emissivity -

$\epsilon \quad$ Total strain -

$\epsilon_{f}^{\prime} \quad$ Fatigue ductility coefficient -

$\dot{\epsilon} \quad$ Total strain rate $\mathrm{s}^{-1}$

$\epsilon_{e} \quad$ Elastic strain

$\dot{\epsilon}_{e} \quad$ Elastic strain rate $\quad \mathrm{s}^{-1}$

$\epsilon_{p} \quad$ Plastic strain -

$\dot{\epsilon_{p}} \quad$ Plastic strain rate $\quad \mathrm{s}^{-1}$

$\lambda \quad$ Wavelength $\mathrm{m}$

$\nu \quad$ Poisson's ratio -

$\nu_{F h} \quad$ Air cinematic viscosity $\mathrm{m}^{2} \mathrm{~s}^{-1}$

$\nu_{F T} \quad$ Air thermal diffusivity $\mathrm{m}^{2} \mathrm{~s}^{-1}$

$\Omega \quad$ Volume variable $\mathrm{m}^{3}$

$\dot{\pi} \quad$ Entropy generation flow $\quad \mathrm{W} \mathrm{m}^{-3} \mathrm{~K}^{-1}$ 


$\begin{array}{llr}\psi & \text { Helmholtz specific free energy } & \mathrm{J} \mathrm{kg}^{-1} \\ \dot{\psi} & \text { Helmholtz specific free energy flux } & \mathrm{W} \mathrm{kg}^{-1} \\ \rho & \text { Material density } & \mathrm{kg} \mathrm{m}^{-3} \\ \sigma & \text { Stress tensor } & \mathrm{J} \mathrm{m}^{-3} \\ \varsigma & \text { Stefan Boltzmann constant } & \mathrm{Wm}^{-2} \mathrm{~K}^{-4} \\ \sigma_{f}^{\prime} & \text { Fatigue strength coefficient } & \mathrm{Pa} \\ \tau & \text { Time constant } & \mathrm{s} \\ \theta_{T} & \text { Mean temperature difference between specimen and environment } & \mathrm{K} \\ \dot{\theta}_{T} & & \text { Mean temperature difference variation }\end{array}$




\section{References}

[1] S. S. Manson, Fatigue : A complex subject - some simple approximations, Experimental Mechanics 5 (1964) 193 - 226.

[2] L. F. Coffin, A note on low cycle fatigue laws, Journal of Materials 6 (2) (1971) $388-402$.

[3] J. Morrow, Cyclic plastic strain energy and fatigue of metals, ASTM STP 378 (1965) $45-87$.

[4] G. R. Halford, The energy required for fatigue, Journal of Materials 1 (1966) $3-18$.

[5] J. Park, D. Nelson, Evaluation of an energy-based approach and a critical plane approach for predicting constant amplitude multiaxial fatigue life, International Journal of Fatigue 22 (1) (2000) 23 - 39. doi:http://dx.doi.org/10.1016/S0142-1123(99)00111-5.

URL http://www.sciencedirect.com/science/article/pii/ S0142112399001115

[6] A. Lipski, S. Mroziński, Approximate determination of a straincontrolled fatigue life curve for aluminum alloy sheets for aircraft structures, International Journal of Fatigue 39 (2012) 2 7, physical and phenomenological approaches to fatigue damage. doi:http://dx.doi.org/10.1016/j.ijfatigue.2011.08.007.

URL http://www.sciencedirect.com/science/article/pii/ S0142112311002064

[7] Q. Guo, X. Guo, J. Fan, R. Syed, C. Wu, An energy method for rapid evaluation of high-cycle fatigue parameters based on intrinsic dissipation, International Journal of Fatigue 80 (2015) 136 - 144. doi:http://dx.doi.org/10.1016/j.ijfatigue.2015.04.016.

URL http://www.sciencedirect.com/science/article/pii/ S0142112315001322

[8] G. Fargione, A. Geraci, G. L. Rosa, A. Risitano, Rapid determination of the fatigue curve by the thermographic method, International Journal of Fatigue 24 (1) (2002) 11 - 19. doi:http://dx.doi.org/10.1016/S01421123(01)00107-4. 
URL http://www.sciencedirect.com/science/article/pii/ S0142112301001074

[9] G. La Rosa, A. Risitano, Thermographic methodology for rapid determination of the fatigue limit of materials and mechanical components, International Journal of Fatigue 22 (1) (2000) 65 - 73. doi:http://dx.doi.org/10.1016/S0142-1123(99)00088-2.

URL http://www.sciencedirect.com/science/article/pii/ S0142112399000882

[10] G. Meneghetti, M. Ricotta, The use of the specific heat loss to analyse the low- and high-cycle fatigue behaviour of plain and notched specimens made of a stainless steel, Engineering Fracture Mechanics 81 (2012) 2 16. doi:http://dx.doi.org/10.1016/j.engfracmech.2011.06.010.

URL http://www.sciencedirect.com/science/article/pii/ S0013794411002347

[11] M. Amiri, M. M. Khonsari, Rapid determination of fatigue failure based on temperature evolution: Fully reversed bending load, International Journal of Fatigue 32 (2) (2010) 382 - 389. doi:http://dx.doi.org/10.1016/j.ijfatigue.2009.07.015.

URL http://www.sciencedirect.com/science/article/pii/ S0142112309002382

[12] M. Liakat, M. Khonsari, An experimental approach to estimate damage and remaining life of metals under uniaxial fatigue loading, Materials and Design 57 (2014) 289 - 297. doi:http://dx.doi.org/10.1016/j.matdes.2013.12.027.

URL http://www.sciencedirect.com/science/article/pii/ S0261306913011606

[13] M. Mehdizadeh, M. Khonsari, On the application of fracture fatigue entropy to variable frequency and loading amplitude, Theoretical and Applied Fracture Mechanics 98 (2018) 30 - 37. doi:https://doi.org/10.1016/j.tafmec.2018.09.005.

URL http://www.sciencedirect.com/science/article/pii/ S016784421830329X

[14] P. Ribeiro, D. Queiros-Condé, L. Grosu, L. Gallimard, An exergetic approach for materials fatigue, International Journal of Exergy 22 (3) 
(2017) 235-249. doi:10.1504/IJEX.2017.083172.

URL https://www.inderscienceonline.com/doi/abs/10.1504/ IJEX . 2017.08317

[15] J. Lemaitre, J. Chaboche, Mechanics of Solid Materials, Cambridge University press, Cambridge UK, 1990.

[16] M. Khonsari, M. Amiri, Introduction to thermodynamics of Mechanical Fatigue, CRC press, Boca Raton, 2017.

[17] M. Naderi, M. Amiri, M. M. Khonsari, On the thermodynamic entropy of fatigue fracture, Proceedings of the Royal Society of London A: Mathematical, Physical and Engineering Sciences 466 (2114) (2010) 423-438. doi:10.1098/rspa.2009.0348.

URL http://rspa.royalsocietypublishing.org/content/466/ $2114 / 423$

[18] M. Naderi, M. Khonsari, An experimental approach to lowcycle fatigue damage based on thermodynamic entropy, International Journal of Solids and Structures 47 (6) (2010) 875 - 880. doi:http://dx.doi.org/10.1016/j.ijsolstr.2009.12.005.

URL http://www.sciencedirect.com/science/article/pii/ S0020768309004703

[19] A. Bäumel, T. Seeger, Materials data for cyclic loading, Elsevier Science Publishers, 1990.

[20] M. Meggiolaro, J. Castro, Statistical evaluation of strain-life fatigue crack initiation predictions, International Journal of Fatigue 26 (5) (2004) 463 - 476. doi:http://dx.doi.org/10.1016/j.ijfatigue.2003.10.003. URL http://www. sciencedirect.com/science/article/pii/ S0142112303002469

[21] A. Ince, G. Glinka, A modification of morrow and smithwatsontopper mean stress correction models, Fatigue \& Fracture of Engineering Materials \& Structures 34 (11) 854-867. doi:10.1111/j.14602695.2011.01577.x.

URL https://onlinelibrary.wiley.com/doi/abs/10.1111/j. 1460-2695.2011.01577. $\mathrm{x}$ 
[22] N. E. Dowling, Mean stress effects in stress-life and strain-life fatigue, in: SAE Technical Paper, SAE International, 2004. doi:10.4271/200401-2227.

URL https://doi.org/10.4271/2004-01-2227

[23] G. Meneghetti, Analysis of the fatigue strength of a stainless steel based on the energy dissipation, International Journal of Fatigue 29 (2007) 81 -94 .

[24] T. Boulanger, A. Chrysochoos, C. Mabru, A. Galtier, Calorimetric analysis of dissipative and thermoelastic effects associated with the fatigue behavior of steels, International Journal of Fatigue 26 (3) (2004) 221 - 229. doi:http://dx.doi.org/10.1016/S0142-1123(03)00171-3.

URL http://www.sciencedirect.com/science/article/pii/ S0142112303001713

[25] A. Blanche, A. Chrysochoos, N. Ranc, V. Favier, Dissipation assessments during dynamic very high cycle fatigue tests, Experimental Mechanics 55 (4) (2015) 699-709. doi:10.1007/s11340-014-9857-3.

URL http://dx.doi.org/10.1007/s11340-014-9857-3

[26] A. Chrysochoos, J.-C. Chezeaux, H. Caumon, Analyse thermomécanique des lois de comportement par thermographie infrarouge, Rev. Phys. Appl. (Paris) 24 (2) (1989) 215-225. doi:10.1051/rphysap:01989002402021500.

URL http://dx.doi.org/10.1051/rphysap:01989002402021500

[27] A. Chrysochoos, R. Peyroux, Analyse expérimentale et modélisation numérique des couplages thermomécaniques dans les matériaux solides, Revue Générale de Thermique 37 (7) (1998) 582 - 606. doi:http://dx.doi.org/10.1016/S0035-3159(98)80036-6.

URL http://www.sciencedirect.com/science/article/pii/ S0035315998800366

[28] A. Chrysochoos, H. Louche, An infrared image processing to analyse the calorific effects accompanying strain localisation, International Journal of Engineering Science 38 (16) (2000) 1759 - 1788. doi:http://dx.doi.org/10.1016/S0020-7225(00)00002-1.

URL http://www.sciencedirect.com/science/article/pii/ S0020722500000021 
[29] E. M. Pellegrino, E. Ghibaudi, L. Cerruti, Clausius disgregation: A conceptual relic that sheds light on the second law, Entropy 17 (7) (2015) 4500-4518. doi:10.3390/e17074500.

URL http://www.mdpi.com/1099-4300/17/7/4500

[30] M. Gouy, Sur l'énergie utilisable, Journal de physique théorique et appliquée 8 (1) (1889) 501 - 518.

[31] J. Keenan, Availability and irreversibility in thermodynamics, British Journal of Applied Physics 2 (7) (1951) 183 - 192.

[32] J. C. Dixon, Appendix B: Properties of Air, Wiley-Blackwell, 2007, pp. 375-378. doi:10.1002/9780470516430.app2.

URL https://onlinelibrary.wiley.com/doi/abs/10.1002/ 9780470516430.app2

[33] B. Eyglunent, Manuel de thermique théorie et pratique (2e éd.), Hermès, 1997.

[34] M. Ashjaee, M. Amiri, J. Rostami, A correlation for free convection heat transfer from vertical wavy surfaces, Heat and Mass Transfer 44 (1) (2007) 101-111. doi:10.1007/s00231-006-0221-8.

URL http://dx.doi.org/10.1007/s00231-006-0221-8

[35] M. F. Modest, Radiative heat transfer, 3rd Edition, Elsevier, 2013.

[36] S. M. Baumann, Direct emissivity measurements of painted metals for improved temperature estimation during laser damage testing, Ph.D. thesis, Air Force Institute of Technology (2014). 